\title{
Learning from Failure; Hypoxia Is an Evil Foe
}

\author{
Rodney J. Hicks \\ The Sir Peter MacCallum Department of Oncology, The Peter MacCallum Cancer Centre, University of Melbourne, Melbourne, \\ Australia
}

\section{See the associated article on page 1045.}

$\mathbf{M}$ icrosoft founder Bill Gates once said, "Success is a lousy teacher. It seduces smart people into thinking they can't lose." The corollary of this is that failure can be instructive. I am sure that the authors of the elegantly designed and methodologically rigorous study reported by Vera et al. (1) would have been disappointed when they analyzed their results and found that they had failed to achieve, by radiation dose escalation, their primary aim of improving outcomes of patients identified as having hypoxic non-small cell lung cancer (NSCLC). Nevertheless, they are commended for their effort and we can learn a lot from their failure. As Sir Winston Churchill once commented, "However beautiful the strategy, you should occasionally look at the results."

The premise of the study was sound. It has been proven, through the seminal work of L.H. Gray more than $50 \mathrm{y}$ ago, that hypoxia increases radioresistance (2). Furthermore, the presence of hypoxia leads to complex changes in tumor biology, which include alterations in cellular metabolism (3), impaired DNA repair, and resulting genomic instability (4). Many of these effects are mediated by genes in the hypoxia-inducible factor (HIF) heterodimer. $\mathrm{HIF}$ target genes include $M Y C$ - which increases expression of the glucose 1 transporter — and hexokinase (5)—which, in turn, drives glycolytic metabolism. Additional effects include increased angiogenesis and tumor growth (6). Studies in NSCLC have demonstrated that increased HIF expression in NSCLC is both prevalent and adversely affects overall survival (7). There is also evidence that hypoxia can be imaged in NSCLC and is associated with an adverse prognosis (8).

Accordingly, increasing radiation dose is a logical means to overcome the radioresistance and adverse prognostic implications associated with hypoxia. However, dose-limiting toxicity in adjacent tissues mandates that this can be achieved only by reducing radiation treatment volumes (9). To address this challenge, a consortium of 15 academic PET facilities sought to mitigate the poor outcomes in NSCLC treated with radiotherapy by escalating radiation to

Received Mar. 18, 2017; revision accepted Mar. 20, 2017.

For correspondence or reprints contact: Rodney J. Hicks, The Sir Peter MacCallum Department of Oncology, The Peter MacCallum Cancer Centre, University of Melbourne, 305 Grattan St., Melbourne, Victoria 3000, Australia. E-mail: rod.hicks@petermac.org

Published online Mar. 30, 2017.

COPYRIGHT (c) 2017 by the Society of Nuclear Medicine and Molecular Imaging. DOI: 10.2967/jnumed.117.191510 subregions identified to be hypoxic on ${ }^{18} \mathrm{~F}$-misonidazole $\left({ }^{18} \mathrm{~F}\right.$ FMISO) PET/CT. Within tolerance, radiation dose was increased to up to $86 \mathrm{~Gy}$ in patients who had positive ${ }^{18} \mathrm{~F}$-FMISO PET/CT studies compared with a planned treatment of $66 \mathrm{~Gy}$ in the absence of hypoxia. Despite this therapeutic intervention, the presence of imageable hypoxia remained strongly predictive of adverse diseasefree survival, with a trend also for adverse overall survival, despite failing to reach statistical significance. Moreover, in patients with positive ${ }^{18} \mathrm{~F}$-FMISO scans, there was no difference in disease-free survival of patients with positive ${ }^{18}$ F-FMISO PET in whom dose could be escalated compared with those in whom dose was limited to $66 \mathrm{~Gy}$, and both groups had worse disease-free survival than patients with negative ${ }^{18} \mathrm{~F}-\mathrm{FMISO}$ studies who received standard therapy. Additionally, response (complete response and partial response) at 3 mo after radiotherapy based on RECIST 1.1 in the ${ }^{18}$ F-FMISO-positive patients was seen in 12 of $24(50 \%$ [95\% confidence limits, 31\%-69\%]) after the escalated radiotherapy doses and in 5 of 10 (50\% [95\% confidence limits, 24\%-76\%]) after 66 Gy. So, the study failed to achieve its primary aim of improving response rates by dose escalation.

What can we salvage from this experience? First, the authors have demonstrated that implementing complex multicenter trials that use PET as an imaging biomarker to guide adaptive therapies is feasible. Second, they have confirmed earlier studies that suggested that hypoxia as imaged by PET has a reasonably high prevalence in NSCLC (10) and again demonstrated the adverse prognostic significance of imageable hypoxia, which has also been shown in head and neck cancer using ${ }^{18} \mathrm{~F}-\mathrm{FMISO}$ PET (11). Finally, and perhaps most importantly, these data suggest that the modest increments on radiation dose that are achievable in a clinical setting are probably insufficient to overcome the radioresistance imparted by hypoxia, or the influence of hypoxia on a tumor's predisposition for tissue invasion and metastatic spread (12), which may lead to adverse outcomes even in the setting of adequate local disease control.

The challenge of overcoming hypoxia by simply increasing radiation dose is underpinned by the so-called oxygen-enhancement ratio, which is the degree to which oxygenation increases radiosensitivity. Conversely, the oxygen-enhancement ratio influences the radiation dose required to overcome hypoxia. Depending of the extent of hypoxia, this may be a factor of 2-3 and is probably not achievable with conventional radiotherapy techniques. It is also important to recognize that hypoxia is not the only cause of treatment failure. This was emphasized by Rod Withers' 4Rs, namely, Repair of sublethal/potentially lethal damage; Reassortment of surviving cells within the division cycle; Reoxygenation of erstwhile hypoxic cells during fractionated treatment; and 
Repopulation of surviving clonogenic cells during a course of treatment, to which a fifth R (Radiosensitivity of clonogenic cells) has since been added (13).

An alternative approach to overcome the adverse significance of hypoxia has been to use it as a therapeutic target by combining hypoxiaactivated cytotoxic chemotherapy agents, such as tirapazamine, with external-beam radiotherapy. Preliminary studies in advanced head and neck cancer demonstrated both a high prevalence of imageable hypoxia and response to this combination (14) and led to a randomized phase II trial of chemoradiation with and without tirapazamine, which confirmed the benefit of adding a hypoxia-sensitizing agent to radiation in the presence of ${ }^{18} \mathrm{~F}$-FMISO uptake in head and neck tumors (15). Despite the promise of this therapy, it failed to improve the outcome in a phase III study that lacked cohort enrichment for, or even characterization of, tumor hypoxia (16). A subgroup analysis of patients within this trial who had undergone hypoxia imaging with an alternative hypoxia-imaging agent, ${ }^{18} \mathrm{~F}$-fluoro-azomycin-aribinoside ( $\left.{ }^{18} \mathrm{~F}-\mathrm{FAZA}\right)$, demonstrated again the prognostic significance of hypoxia on PET imaging with patients with a positive ${ }^{18} \mathrm{~F}$-FAZA result PET treated with conventional chemoradiation having a significantly worse prognosis than those receiving radiation with tirapazamine (17). Studies combining novel radiosensitizing agents with radiation in patients with positive PET hypoxia-imaging studies may be warranted in light of these studies. The presence of hypoxia, by invoking genomic instability, may also increase neoantigenic challenge and underlie the favorable responses being seen with immunotherapy in patients with advanced NSCLC (18). This may also be relevant to radiotherapy outcomes, with evidence that there may be synergy between radiation and check-point immunotherapy (19).

Clearly, hypoxia remains an evil foe in our battle to achieve better outcomes in non-small cell cancer but by demonstrating its importance, Vera et al. (1) pose us the challenge to design new combination therapies. As indicated by Amos Bronson Alcott, "Success is sweet and sweeter if long delayed and gotten through many struggles and defeats."

\section{DISCLOSURE}

No potential conflict of interest relevant to this article was reported.

\section{REFERENCES}

1. Vera P, Thureau S, Chaumet-Riffaud P, et al. Phase II study of a radiotherapy total dose increase in hypoxic lesions identified by ${ }^{18} \mathrm{~F}$-misonidazole PET/CT in patients with non-small cell lung carcinoma (RTEP5 study). J Nucl Med. 2017;58:1045-1053.

2. Gray LH, Conger AD, Ebert M, Hornsey S, Scott OC. The concentration of oxygen dissolved in tissues at the time of irradiation as a factor in radiotherapy. Br J Radiol. 1953;26:638-648.
3. Kim JW, Tchernyshyov I, Semenza GL, Dang CV. HIF-1-mediated expression of pyruvate dehydrogenase kinase: a metabolic switch required for cellular adaptation to hypoxia. Cell Metab. 2006;3:177-185.

4. Bristow RG, Hill RP. Hypoxia and metabolism: hypoxia, DNA repair and genetic instability. Nat Rev Cancer. 2008;8:180-192.

5. DeBerardinis RJ, Lum JJ, Hatzivassiliou G, Thompson CB. The biology of cancer: metabolic reprogramming fuels cell growth and proliferation. Cell Metab. 2008;7:11-20.

6. Jiang BH, Agani F, Passaniti A, Semenza GL. V-SRC induces expression of hypoxia-inducible factor 1 (HIF-1) and transcription of genes encoding vascular endothelial growth factor and enolase 1: involvement of HIF-1 in tumor progression. Cancer Res. 1997;57:5328-5335.

7. Giatromanolaki A, Koukourakis MI, Sivridis E, et al. Relation of hypoxia inducible factor 1 alpha and 2 alpha in operable non-small cell lung cancer to angiogenic/molecular profile of tumours and survival. Br J Cancer. 2001; 85:881-890.

8. Eschmann SM, Paulsen F, Reimold M, et al. Prognostic impact of hypoxia imaging with ${ }^{18} \mathrm{~F}$-misonidazole PET in non-small cell lung cancer and head and neck cancer before radiotherapy. J Nucl Med. 2005;46:253-260.

9. van Baardwijk A, Wanders S, Boersma L, et al. Mature results of an individualized radiation dose prescription study based on normal tissue constraints in stages I to III non-small-cell lung cancer. J Clin Oncol. 2010;28:1380-1386.

10. Trinkaus ME, Blum R, Rischin D, et al. Imaging of hypoxia with ${ }^{18}$ F-FAZA PET in patients with locally advanced non-small cell lung cancer treated with definitive chemoradiotherapy. J Med Imaging Radiat Oncol. 2013;57: 475-481.

11. Rajendran JG, Schwartz DL, O'Sullivan J, et al. Tumor hypoxia imaging with [F-18] fluoromisonidazole positron emission tomography in head and neck cancer. Clin Cancer Res. 2006;12:5435-5441.

12. Pennacchietti S, Michieli P, Galluzzo M, Mazzone M, Giordano S, Comoglio PM. Hypoxia promotes invasive growth by transcriptional activation of the met protooncogene. Cancer Cell. 2003;3:347-361.

13. Thames HD, Peters LJ, McBride WH, Mason KA. The origins of translational radiation oncology: in memoriam $H$. Rodney Withers (21 September 1932-25 February 2015). Radiother Oncol. 2015;115:1-2.

14. Hicks RJ, Rischin D, Fisher R, Binns D, Scott AM, Peters LJ. Utility of FMISO PET in advanced head and neck cancer treated with chemoradiation incorporating a hypoxia-targeting chemotherapy agent. Eur J Nucl Med Mol Imaging. 2005;32:1384-1391.

15. Rischin D, Hicks RJ, Fisher R, et al. Prognostic significance of $\left[{ }^{18} \mathrm{~F}\right]$-misonidazole positron emission tomography-detected tumor hypoxia in patients with advanced head and neck cancer randomly assigned to chemoradiation with or without tirapazamine: a substudy of Trans-Tasman Radiation Oncology Group Study 98.02. J Clin Oncol. 2006;24:2098-2104.

16. Rischin D, Peters LJ, O'Sullivan B, et al. Tirapazamine, cisplatin, and radiation versus cisplatin and radiation for advanced squamous cell carcinoma of the head and neck (TROG 02.02, HeadSTART): a phase III trial of the Trans-Tasman Radiation Oncology Group. J Clin Oncol. 2010;28:2989-2995.

17. Graves EE, Hicks RJ, Binns D, et al. Quantitative and qualitative analysis of $\left[{ }^{18} \mathrm{~F}\right] \mathrm{FDG}$ and $\left[{ }^{18} \mathrm{~F}\right] \mathrm{FAZA}$ positron emission tomography of head and neck cancers and associations with HPV status and treatment outcome. Eur J Nucl Med Mol Imaging. 2016;43:617-625.

18. Rittmeyer A, Barlesi F, Waterkamp D, et al. Atezolizumab versus docetaxel in patients with previously treated non-small-cell lung cancer (OAK): a phase 3, open-label, multicentre randomised controlled trial. Lancet. 2017;389: 255-265.

19. Sharabi AB, Lim M, DeWeese TL, Drake CG. Radiation and checkpoint blockade immunotherapy: radiosensitisation and potential mechanisms of synergy. Lancet Oncol. 2015;16:e498-e509. 